\title{
HUMANIDADES, HUMANISMO: AMBIGÜEDADES Y PEAJES IDEOLOGICOS
}

Francisco SAMARANCH KIRNER

Dpto. de Filosofía, UNED.

I.

1. Preguntar si es o no pertinente promover los estudios humanísticos en general $y$, en particular, los de las humanidades clásicas, en una denominada era tecnológica, parece presuponer por los menos un par de cosas: a) que, de no ser por la incómoda presencia de esa propensión tecnológica, la pertinencia en cuestión sería algo prácticamente indiscutible; y b) que la tecnología invasora o bien i) es portadora de algún valor de superior rango que hace caduca aquella pertinencia en favor de otra cosa, o bien ii) simplemente ha hecho las veces de catalizador, poniendo al descubierto lo inadecuado o insuficiente de las razones que apoyaban aquella pertinencia.

Ahora bien, por lo que toca al supuesto a), no sólo parece necesario afirmar que la presunta pertinencia no ha sido unánimemente aceptada como indiscutible, sino que -y eso es lo que resulta especialmente significativo- las razones que se han aducido a su favor han estado mayoritariamente contaminadas por factores ideológicos de distinta clase, ya sea en la modalidad más agresiva de la política o las instituciones, ya en las mucho más sutiles que podemos abarcar bajo el epígrafe de la "canonicidad". Y, por lo que respecta al punto b), dado que en principio parece tener poco sentido que la mencionada invasión tecnológica pueda suponer por sí misma alternativa válida a una formación humanística -por la radical heterogeneidad entre ambas cosas-, habrá que considerar la hipótesis ii) y replantearse en consecuencia toda la cuestión,

Éndoxa: Series Filosoficas, $n^{\circ} 2,1993$, UNED, Madrid:

Francisco Samaranch Kimer: Humanidades, humanismo: ambigüedades y peajes idealógicos. pp. 61-95 
especialmente en lo que toca a las razones y motivos que puedan abogar por una tal formación.

Esto supuesto, la pregunta inicial acerca de si es o no pertinente una formación humanística en un mundo de predominio tecnológico, deberá ser reformulada de modo que haga más patente la complejidad del problema. Es decir, ante la comprobación de que los estudios humanísticos -y muy en particular los clásicos- están siendo desplazados por otra clase de intereses, preferentemente vinculados-a o dimanantes-de la tecnología, tendremos que preguntarnos: 19) $^{9}$ qué clase de razones han justificado tradicionalmente los estudios de humanidades, en especial las clásicas; $2^{2}$ ) por qué han perdido fuerza estas razones, qué las ha minado internamente o qué las ha desplazado desde fuera; y $-3^{2}$ ) si es posible aún encontrar razones eficazmente suasorias que hagan pertinente la opción por esa clase de estudios, si hay aún algo que nos permita afirmar con Italo Calvino ${ }^{1}$ que «leer los clásicos es mejor que no leer los clásicos», justificando al propio tiempo por qué es mejor.

Al reformular de esta manera la pregunta inicial, hemos señalado cuáles van a ser los tópicos que va a examinar el ensayo la manipulación ideológica de los estudios clásicos en sus dos formas, la político-institucional y la "canónica"-, y hemos ofrecido el diseño estructural del mismo.

\section{II.}

2. En el marco de la occidentalidad cristiana naciente (sin ánimo de considerar el hecho enteramente excepcional: cosas así tienden a ocurrir en las culturas con escritura), la clasicidad greco-romana parece fatal y oficialmente condenada de iure al saqueo y la manipulación ideológicos ya en el célebre principio agustiniano expuesto en el DE DOCTRINA CHRISTIANA ${ }^{2}$ : Philosophi autem qui

${ }^{1}$ 1992; 20.

2 II. c. $40 ; 60$. 
vocantur, si qua forte vera et fidei nostrae accommodata dixerunt, maxime Platonici, non solum formidanda non sunt, sed ab eis etiam tamquam iniustis possessoribus in usum nostrum vindicanda (En cuanto a los filósofos, si por casualidad han dicho alguna cosa verdadera y conforme a nuestra fe, en particular los Platónicos, no sólo no debe ser temida, antes hay que, como a poseedores injustos, reivindicársela a ellos para nuestro uso). $Y$, para que no nos quepa duda alguna acerca del alcance de lo que dice, aduce en su favor que también Dios ordenó al pueblo de Israel llevarse de Egipto "vasos y alhajas de oro y plata y vestidos", a fin de "hacer de ellos mejor uso" que los egipcios.

Así pues, desde su presunta posesión de la verdad intemporal de la revelación, el obispo de Hipona encuentra fundado derecho a hacer suya, ante la posesión "injusta" de los no creyentes, cualquier brizna de verdad o valor útil que contuviera cualquier texto no cristiano. De esta manera la errante trayectoria temporal de la clasicidad pagana quedaría salvíficamente subsumida en la intemporal verdad del cristianismo, o abandonada a su oscura suerte. En cuanto a la flagrante falacia jurídica que gravita en torno al "iniustis" y a su correlativo "vindicanda", es suficientemente clara como para detenernos ahora en ella.

No cabe duda de que, en calidad de ejemplo de lo que hemos denominado ideología agresiva o dura, el texto citado no tiene desperdicio. Otra cosa es que el alegato agustiniano tuviera el efecto que pudo desear su autor. De hecho, los restos de la clasicidad greco-romana se mantuvieron en su vía de supervivencia, más o menos precaria, en los avatares de los siglos subsiguientes, y reaparecieron algunos siglos más tarde para ser de nuevo objeto de manipulación ideológica, sólo que ahora desde una postura de valoración positiva.

3. Tomamos como primera muestra de esa pequeña crónica un suceso profundamente ambiguo, pero decididamente simbólico. Ambiguo no sólo por su misma constitución en cuanto hecho, sino también porque, en la radicalidad misma de su postura agresiva, 
se encuentra uno de los prototipos de ideología blanda que habremos de considerar luego. Se trata de la aparición de la autodenominada cultura "moderna".

Respecto a ella escribe Jacques Le Goff": «la cultura moderna (la del Humanismo y la del Renacimiento) nace precisamente en contra de la que en aquellos momentos venía siendo la cultura moderna -la de la Edad Media- y en nombre de la cultura antigua, griega y romana». Cultura que "se prefería a la de los 'modernos', considerados como una progresiva decadencia, en cuanto que suponía un alejamiento de los modelos". Esa especie de "retorno al paradigma original", con el calambre semántico de llamar 'moderno' a lo que parecía un retroceso, iba a tener especial fortuna en momentos en que se quería imprimir a las estructuras o instituciones político-sociales un fuerte golpe de timón en algún sentido "revolucionario".

Es de sobre conocida la presencia de referencias clásicas en la Revolución Francesa o en el dominio napoleónico. Recordemos cómo «los jacobinos se vieron a sí mismos... a través del mito de los filósofos estoicos»". Y cómo, para obviar la identificación que estableciera Montesquieu entre democracia ateniense y vida de lujo, buscaron el "rigor revolucionario" en una Esparta mitificada y ahistórica ${ }^{6}$. Al menos hasta que los termidorianos les recordaron que el régimen espartano sólo fue posible gracias a la esclavitud... O de qué manera el bonapartismo manejará el modelo cesarista, etc. En cualquier caso, no se puede dejar de tener en cuenta hasta qué punto ese uso de las referencias clásicas es subsidiario de un desconocimiento crítico del modelo empleado.

Pero no es esto lo que prioritariamente nos interesa abordar ahora, sino cómo se da esa manipulación en el ámbito más específico de los estudios clásicos como tales.

\footnotetext{
${ }^{3}$ Enciclopedia Einaudi, voz antico/moderno; Canfora 1991, 5.

${ }^{4}$ Canfora 1991, 241.

${ }^{5}$ Canfora 1991, 6.

${ }^{6}$ Ver Canfora, ibid, 19.
} 
4. Fue precisamente la cuestión de la esclavitud y la colateral y más amplia de la igualdad absoluta o sólo proporcional (según el modelo platónico-aristotélico) lo que destapó el frasco de las discrepancias y la polémica, y la que fundó una primera polarización en cuanto al valor de los estudios clásicos: «la cultura 'antidemocrática' les otorgará, por lo general, un papel relevante, mientras que, por el contrario, serán puestos en discusión en aquellos lugares en los que se lleven a cabo experimentos de 'cultura de masas' ${ }^{7}$. Así, en una página de MEIN KAMPF', se nos dice que «la educación básica debe ser siempre ideal, debe corresponder siempre a las disciplinas humanísticas y procurar tan sólo bases para una posterior especialización científica»; y que «sobre todo no debe permitirse que -en la enseñanza de la Historia- se menosprecie el estudio de la Antigüedad". Porque «una civilización lucha por su existencia, una civilización que sintetiza en su seno milenios y que abarca a su vez el helenismo y el germanismo». Por el contrario, Trotsky, en su esbozo biográfico de Lenin', definirá «los estudios clásicos como un 'instrumento de tortura' propedéutico para la asimilación de la ideología zarista».

Esta polarización no sólo se muestra enormemente polimorfa y variable, sino que se entreteje con otras muchas formas de pensamiento, estableciendo lazos de cercanía y parentesco entre gentes en todo lo demás radicalmente opuestas: recuérdese, p.e., la compartida repulsión hacia "el rebaño" y la exaltación de la "individualidad" en figuras tan antitéticas en el resto de lo que fueron como Nietzsche y Wilamowitz.

Esto dificulta cualquier morfología taxonómica -que implicaría reiteraciones y encabalgamientos poco clarificadores y engorrosos-, poco útiles por lo demás a lo que aquí se pretende. Vamos a

${ }^{7}$ Canfora Ib. 10

${ }^{8}$ Ed. 1939, 469-70; Canfora, Ib. 10.

${ }^{9}$ EL JOVEN LENIN, 1936: ver Canfora Ib. 10. 
ceñirnos, pues, simplemente a algunas referencias históricas que nos parecen especialmente ilustrativas.

5. Particularmente significativo para nuestro propósito es el caso de Alemania. Para abordar la cuestión de cómo se justifican ahí los estudios clásicos y de a qué fines se pretende que sirvan, es conveniente tener presentes un par de cuestiones previas. En primer lugar hay que recordar, como señala Canfora ${ }^{10}$, que «la época de los grandes exponentes de los estudios clásicos europeos... (los Estienne, los Scaligeros, Hutten, Lipsius, Godefroy), será la única en la que los estudios clásicos habrían sido 'la cultura moderna'». Todo lo demás, hasta nuestros días, será un mundo de epígonos; fundamental, sin duda, para el conocimiento científico de las civilizaciones griega y romana, pero siempre distinto de aquél en cuanto para estos el prurito de la "modernidad" queda definitivamente separado de los estudios de la clasicidad antigua. Más aún: con mucha y creciente frecuencia, la bandera del considerado "progreso" se situará en el lado opuesto al humanismo clásico. Este cambio de registro es capital, porque consagra la vigencia de un principio de ideología blanda o sutil que habremos de tener muy en cuenta más tarde: la postura de considerar decadentes a los medievales por haberse alejado de los modelos primigenios, «consolidó una concepción del mundo entendido como (un proceso) de caída a partir de un modelo perfecto ${ }^{11}$.

En segundo lugar, tal como se dejará ver en los testimonios que se empleen aquí, toda la cuestión de los estudios clásicos en el medio alemán no podrá separarse a) de la evolución político-social de Alemania desde finales del s. XVIII, incluido el reto nacionalista de asumir la hegemonía política y cultural de Europa cuando palidezca la de Francia; y b) del hecho, mucho menos explicitado habitualmente, pero no menos decisivo por ser menos aparente, de que en Alemania, a diferencia de otros países de obediencia

\footnotetext{
${ }^{10}$ Ib. 241.

${ }^{11}$ Canfora, ib. 241.
} 
católica post-tridentina, los estudios escriturísticos -vétero y neotestamentarios- han seguido siendo ocupación importante de las universidades, que han podido desarrollar en torno a ellos una avanzada técnica filológica. Es realmente incalculable cuánto recibe de ésta, para bien y para mal, la filología clásica.

6. Esto supuesto, un primer dato a tener en cuenta son las razones de fondo que apoyan la preferencia alemana por el clasicismo griego frente al romano. Si las referencias y simbología que dominan los prolegómenos y culminación de la Revolución Francesa son estadísticamente "romanas"12, en Alemania se encuentra una decidida opción por lo griego. La preferencia está ya expuesta en la crítica antifrancesa y filohelénica de von Humboldt en el $1800^{13}$, así como en su concepción del griego como Bildungsfundament del hombre alemán en sus intentos de reforma educativa (1808-1809). Algo más de un siglo después, Eduard Schwartz hilvanará toda una reflexión explicativa del hecho. En GYMNASIUM UND WELTKULTUR ${ }^{14}$, nos dirá que, por supuesto, «tanto para el mundo romano como para el mundo germánico, es el Imperio romano el presupuesto común, además del portador de la cultura antigua, incluyendo en ella sus elementos griegos». Ahora bien, «hasta la Revolución Francesa, la lengua de la Iglesia, y también la de la ciencia vinculada a la Iglesia, seguía siendo el latín, incluso después de la división de Europa en Estados nacionales. Será con la Revolución Francesa y con el consiguiente despertar de la 'conciencia nacional' de los pueblos, cuando se ponga fin a la hegemonía del latín. En el momento muy conflictivo de la rebelión antinapoleónica, el 'neohumanismo' alemán sabrá otorgar un papel primordial al griego». De esta manera, la lengua de la Hélade «llegó a superar al latín no en cuanto 'lengua culta', sino como 'portador ideal de aquellos

\footnotetext{
${ }^{12}$ Ver Vidal-Naquet, 1976; 20.

${ }^{13}$ Ver Canfora, ib. 37.

${ }^{14} 1917$; 212-214. Ver Canfora, ib. 37.
} 
valores que la filosofía clásica alemana asumía, y que creía poder conservar y transmitir sólo a través de la poesía, el arte y la filosofía griega'». En una palabra: «la línea 'latina' de los estudios clásicos europeos desembocó... en la Ilustración y la Revolución» y «la línea griega fue un elemento de liberación (nacional) de la Ilustración y el vehículo del idealismo alemán: Das Griechentum como fundamentación cultural-ideológica de la rebelión contra la democracia igualitaria (...) En este sentido, Niebuhr decía que Alemania es la Grecia de la Edad Moderna».

7. Esos rasgos y muchas de estas ideas no desaparecerán de la escena alemana en los tiempos que van a seguir. De modo que, en el nazismo, estos factores vendrán a combinarse con otros típicos del momento.

"Titular un libro sobre Panecio ANTIKES FÜHRERTUM exige, por lo menos, una explicación. Y Max Pohlenz, que le puso semejante subtítulo a un libro que debería llamarse CICERO DE OFFICIIS UND DAS LEBENSIDEAL DES PANAITIOS ${ }^{15}$, nos da esa explicación al comienzo del Vorwort, recordando que la 'profunda modificación' que se está produciendo en la vida espiritual del pueblo alemán, 'anterior al profundo cambio político' (...), se había manifestado en el campo de la Antigüedad clásica; y por eso en la actualidad ya no tienen valor tesis como la expresada a comienzos del siglo por Richard Reitzenstein, según la cual él ideal de Panecio habría sido el 'supranacional y metapolítico de la humanidad'. Esta visión, continúa Pohlenz, se nos ofrece ya como unilateral: 'el ideal de Panecio no es el de una humanidad genérica, sino el del predominio (Führertum, caudillaje) del hombre superior (...) Impresiona oir hablar de un 'cambio intimo' de la vida espiritual... si se piensa que estas palabras están escritas unos meses después de la inolvidable quema nazi de los libros 'no arios', organizada en

${ }^{15}$ Leipzig-Berlín, 1934. 
Berlín y en las principales ciudades alemanas el 10 de mayo de $1933 »^{16}$.

Esa obsesión por encontrar en la Hélade el prototipo y el precedente paradigmático de lo que se está haciendo, diciendo y pensando en la Alemania de la época, puede llegar a presentar dimensiones grotescas. No se trata ya de la afirmación -tan reiterada y dogmáticamente sostenida cuan poco demostrable en rigor crítico- de la supremacía del alemán como lengua filosófica, sino que se habla de afinidades pre-electivas, de connaturalidad, etc., entre la Grecia clásica y la Alemania nazi. Rodenwaldt, p.e. ${ }^{17}$, dirá que «está claro que para nosotros, los alemanes, el helenismo continúa siendo un valor de percepción inmediata, y Homero siempre significará para nosotros más que Virgilio, etc.» No importa que, a renglón seguido, tenga que reconocer que la arquitectura imperial del Tercer Reich poco tiene que ver con Grecia y sí mucho, por el contrario, con la arquitectura del Imperio Romano...

8. Por lo demás, esa obsesión tiene también algo que ver con la tensión que la mentalidad nazi establece entre lo germano y lo romano. Junto a la «inclinación del Führer hacia el mundo clásico» está «el reclamo constante hacia la 'antigüedad germánica', que provenía de un teórico tan solvente como Rosenberg y de un organizador como Himmler» ${ }^{18}$. De hecho, en el programa nacional socialista del 26 (art. 19), se promovía la derogación del derecho romano y su sustitución por el derecho germánico. No era, pues, de extrañar que esas reservas para con lo romano se invirtieran, con buenos dividendos, en lo griego, mucho menos competitivo y más complementario con lo germánico. Otra cosa es que realmente permitiera hablar objetivamente de afinidad entre la "libre nobleza apolínea" (Dirlmeier) y la nobleza nórdica de los

\footnotetext{
${ }^{16}$ Ver Canfora, 119.

${ }^{17}$ Ver Canfora, $125 \mathrm{~s}$.

${ }^{18}$ Canfora, 128.
} 
germanos. (Nótese que ese germanismo poco o nada parece tener que ver con ese cuarto momento de la historia universal o imperio germánico -luterano, culminador de la absorción de la religión en el Estado-, de la Introducción a las LECCIONES SOBRE LA FILOSOFIA DE LA HISTORIA de Hegel. Por mucho que éste hubiera servido de provocador catalítico).

Dos conceptos están ahí en juego: el de la nordicidad y el del carácter "apolíneo" de lo germano. La idea de lo nordisch no es enteramente nueva, pero sí parece serlo la forma en que la va explotar Schachermeyr. Su tesis central será, en efecto, que «el elemento nórdico que subyace en las poblaciones germánicas únicamente puede emerger mediante la confrontación con otros pueblos 'emparentados por la sangre', o sea, con nórdicos no germánicos ${ }^{19}$. Como recurso para obviar las enormes dificultades históricas que encierra esa sublimación tardía de lo germánico, la teoría no deja de ser ingeniosa. Pero poco más. Y el catálogo de los "Führer nórdicos" surgidos en Grecia, con su culminación en Filipo, "auténtico heredero de los nórdicos macedonios", no hace más que poner en evidencia la debilidad de la propuesta teórica. Que rebasa todo lo imaginable cuando se concluye que la victoria de Roma sobre Cartago se debió a o fue un triunfo de lo nórdico sobre lo semítico ${ }^{20}$.

No se diga nada de la pretensión de ver en lo germánico afinidades profundas con la "libre nobleza apolínea" de los griegos. Aparte de lo que hay de mítico en esa última expresión, no es precisamente apolíneo, en el sentido que la palabra suele recibir, lo que en buena medida diferencia y caracteriza al pensar alemán, mucho más propenso a pensar el absoluto y aun a postularlo por vías cuasi gnósticas que a renunciar a ello en aras de la razón; piénsese, si no, en la mística del s. XIV, en las proclividades gnósticas del idealismo y sus epígonos, o en la pretensión de percepción inmediata de lo helénico de Rodenwaldt.

\footnotetext{
${ }^{19}$ Canfora, 137.

${ }^{20}$ Ver Canfora, 132 ss.
} 
Arrópese todo esto con personajes, mitos y melodías wagnerianas y con ese poso especial de antropología de Dumézil y sus interpretaciones de los mitos germanos ${ }^{21}$; y comprenderemos qué bien redondea todo esto la afirmación de Hitler en MEIN KAMPF ${ }^{22}$ : "sólo los arios son capaces de elaborar la materia, que otros pueblos evidentemente proporcionan, para plasmar una 'civilización', de lo que se deduce la legitimidad de su dominio" ${ }^{23}$

9. Apenas hace falta añadir, para completar esta información sumaria, que esa manipulación se produce en paralelo en la teoría política y la idea del Estado. La pauta de lectura en feed-back será aquí Hegel. De esta manera, desde la teoría de la "democracia germánica" o la teoría del ciudadano soldado (Wilamowitz), el paralelismo entre Macedonia y Prusia que desarrolla Droysen o la especial lectura de la GERMANIA de Tácito y la revaloración del ARMINIUS de von Hutten, hasta la teoría de las élites de Meyer y Gelzer o las sucesivas idealizaciones del estado platónico, incluida -en el postnazismo- la de Kurt von Fritz, no hay nada que no sea consecuente con lo que determinaban premisas acuñadas en el correr de dos siglos. No podemos demorarnos más en ello aquí. Pero sí nos interesa levantar acta de algo que es revelador de un estado de ideología habitual: la postura de «rechazo a las disciplinas que desentronizan el mundo 'clásico' de su tradicional posición emblemática y hegemónica ${ }^{24}$. Una vez más resuenan ecos de aquellos modos de condena que en el siglo XVI poblaban los espacios aledaños de la Inquisición. De esta manera, frente a las matizaciones del hecho religioso que aporta la etnología, el wilamowitziano GLAUBE DER HELLENEN (1931) alardea de que

${ }^{21}$ MYTHES ET DIEUX DES GERMAINS, 1939, 156-157.

22 Ed. cit. 169.

${ }^{23}$ Ver Canfora, 97. Incluso el auge de la investigación en el campo que abre la hipótesis "indoeuropea" parece llevar implícita la obsesión por desterrar del horizonte explicativo de lo griego toda sombra de semitismo: ver, p.e. Burkert 1992, 25 ss., 114 ss., etc.

${ }^{24}$ Canfora, 155. 
«nunca he sabido qué significan palabras como tabú, tótem, etc.». $Y$ Lesky, en sus estudios sobre la tragedia griega ${ }^{25}$, manifiesta el mismo tipo de rechazo: «cuando, en el siglo pasado, aparecieron ante nuestra vista las formas de una cultura primitiva», se encontraron en ciertos pueblos «acciones mímicas, danzas con máscaras, ... que tienen su paralelismo en el más antiguo culto de los griegos». Sin embargo, «los intentos realizados para encontrar aquí las raices de la tragedia griega, han suscitado una viva oposición. Algunas personas se resistían a relacionar uno de los productos más nobles de la cultura griega, incluso de la cultura humana, con las danzas de unos exóticos salvajes... La objeción es en gran parte acertada y nos lleva a considerar que la formación de la tragedia ática en sus fases decisivas debe comprenderse exclusivamente a partir de la cultura helénica y del talento de sus grandes autores" ${ }^{26}$. Nótese la forma entera de decir: no se trata de objeciones críticas, sino de "oposición" y resistencia; basadas no en razones científicas, sino en apreciaciones valorativas personales -los "productos más nobles de la cultura griega" contrastan con los "exóticos salvajes"-. En ningún punto queda un mínimo resquicio para la duda, para la sospecha de estar prejuzgando, de obedecer a un montaje de siglos. Simplemente, de estar defendiendo un "punto de vista"... Nada.

10. No se queda atrás en eso el fascismo. El régimen atribuyó a la cultura clásica, y muy en especial al mito de Roma, una función clave en toda su parafernalia escénica. Promovió dentro del mito, la idea del Imperio "civilizador", para distanciarse del imperio explotador de las potencias coloniales burguesas. la idea permitía también un acercamiento a lo más reaccionario de la Iglesia Católica, cuyo universalismo se pretendía heredero del romano y que había asumido, frente al mundo "moderno", el papel de tutora, conservadora y propagadora de la romanidad, y

\footnotetext{
${ }^{25}$ De 1938; Lesky 1966.

${ }^{26}$ Lesky 1966, $46 \mathrm{~s}$.
} 
que por añadidura coincidía con el fascismo en su oposición al liberalismo y al socialismo ${ }^{27}$.

El pensamiento de la época se apoyará así en una triple continuidad: la que se establece entre la Roma Antigua y la Iglesia Católica; la que se postula entre la Roma Antigua y la Historia de Italia; y la que se construye entre la Roma Antigua y el Fascismo. El alcance salvífico de esta última lo declara sin ambages De Francisci en la voz "Roma", en el DIZIONARIO DI POLITICA A CURA $D E L$ PNF (1940): «la historia enseña que cuando decae Italia todos los horizontes se oscurecen y el mundo se empobrece».

$Y$ en ese marco, dos tópicos a modo de muestra típica: uno el que abarca, en el siglo del Imperio, la figura de Augusto y el canto VI de la ENEIDA virgiliana, con su profecía post eventum. Sin olvidar que también Franco celebró, con un año de retraso, su Semana Augustea en Zaragoza, en 1940; con retraso porque, como aclaraba la crónica de $E M E R I T A^{28}$, en el 39 «todos estaban ocupados en la defensa de la patria».

O el de la mística fascista; que le permite a Ciaceri -por lo demás filólogo bien considerado- afirmar que «somos místicos porque así lo exige la doctrina del fascismo... y porque a ello nos lleva nuestro temperamento de italianos" y porque, en definitiva, también lo fueron los principales autores latinos, diferentes en esto a los griegos... Después de todo, los romanos, incluido el mismo Cicerón, mostraron poca simpatía por la cultura griega. Como dice Canfora ${ }^{29}$, «estamos llegando a lo grotesco».

11. Lo que precede ha sido un muestrario de abusos. No ciertamente una "historia" de los estudios clásicos. Como toma de conciencia de unos ciertos modos de utilización de los estudios humanisticos con determinados fines que no se justifican por sí mismos, debería dejarnos en algún lugar un acre brote de suspica-

\footnotetext{
${ }^{27}$ Ver Canfora, 72-73.

${ }^{28}$ VII, 1939; publicada en el 41; pp. 195-198.

2 Canfora, 75 .
} 
cia o desconfianza: ¿serán otras evaluaciones de lo clásico más inocentes que éstas? Canfora ${ }^{30}$ deja en el aire la posibilidad de ésta y otras preguntas semejantes cuando dice que «la cultura clásica siempre ha sufrido, en el mundo contemporáneo, el complejo de 'estar superada', la conciencia de sentirse superada por el mundo que la rodea (el de la técnica, el de la ciencia, etc.), y por lo general se ha visto afectada por el problema de tener que explicar a los demás su 'necesidad', su papel específico..." A lo que añade que se trata de "un papel para cuyo entendimiento siempre serán necesarias, incluso para un hombre medianamente culto, una serie de mediaciones que no siempre serán obvias» ${ }^{31}$. ¿De dónde podria nacer esta honda ambigüedad que Canfora detecta en lo clásico?.

Las que hemos tomado como manifestaciones de una manipulación ideológica agresiva o dura ocultan, en realidad, un fondo de ideología sutil o blanda, casi imperceptible, embebida incluso en las más diáfanas de las evidencias en que nos movemos -y que son con frecuencia el mejor caldo de cultivo ideológico-: son las que queremos resumir en la idea de "canonicidad". Esta es la cuestión que nos toca abordar ahora.

\section{III.}

12. Comencemos por fijar algunos conceptos.

- El estatuto de "canonicidad" o condición de canon se produce en virtud de «la identificación y estabilización de un cuerpo de textos clásicos o sagrados que es declarado investido de autoridad». Y se efectúa "por obra de un fiat político, eclesiástico o literario. Tales fiat son a menudo confirmados por concilios dotados de altos poderes... $\rangle^{32}$.

\footnotetext{
${ }^{30}$ Canfora, 72 .

${ }^{31} \mathrm{Ib}$.

${ }^{32}$ Henderson 1991, 38.
} 
- Casi todos los cánones -o colecciones "canónicas"- «son antologías complejas reunidas por 'escuelas' o incluso civilizaciones enteras durante largos períodos de tiempo. La Biblia, p.e. ${ }^{33}$. Sin embargo, «como mezcla abigarrada en grado máximo, la epopeya india, el MAHABHARATA, supera incluso a la Biblia y a las escrituras hebreas. (...) (...) Otras escrituras mayores, en particular el QUR'AN, son más homogéneas y unitarias. Pero aun así este libro 'representa una ordenación arbitraria de breves pasajes que habían sido proferidos por el Profeta en distintos tiempos y diversos lugares a lo largo de su vida'. Finalmente la ILIADA y la ODISEA que, debido a sus cualidades literarias más refinadas así como al hecho de haber sido editadas por los eruditos de Alejandría, muestran algo más cercano a un frente unificado, han sido caracterizadas como 'una abigarrada colección de cuentos, tradiciones, leyendas y aun formas que proceden de distintos tiempos y lugares'. En resumen, aunque los clásicos o las escrituras de las distintas tradiciones se diferencian ampliamente unos de otros en su carácter literario y en su orientación intelectual, son al menos iguales en su différance, en su heterogeneidad y disonancia internas» $^{34}$.

- «Una reflexión comparativa revela que la fijación de un canon se produjo, en varias tradiciones mayores, a continuación de una aguda ruptura con el pasado clásico en que los escritos canónicos fueron por primera vez compuestos o revelados. En la tradición judía, p.e. (...) Las catástrofes políticas del primer siglo d. de C., que culminan con la destrucción del Templo de Jerusalén en el año 70 , dieron pie a la definición más formal y definitiva de un canon judío en el Concilio de Jamnia en torno al año $90 \mathrm{~d}$. de $\mathrm{C}$, y al uso de la midrash para interpretar ese canon. También en el Islam, la codificación de la jurisprudencia al comienzo del s. X de nuestra era siguió 'al cierre de la puerta de la ijithad', el fin de la edad

\footnotetext{
${ }^{33}$ Henderson, 21.

${ }^{34}$ Henderson, 22-23.
} 
profética o creativa» ${ }^{35}$. Y así mismo, «como secuela del colapso de la polis griega clásica, Homero fue adicionalmente exaltado en la época helenística, con su conciencia de 'una ruptura definitiva entre el vigoroso pasado y un presente todavía incierto' ${ }^{36}$.

Esto nos daría unos primeros criterios constitutivos de un canon: - la elevación de un corpus de textos a la categoría de paradigma autorizado; - el carácter de antología compleja y multivaria, unificada en virtud de un criterio más bien extrínseco; - la necesidad de que se produzca respecto a tal corpus un fenómeno de "distanciamiento" o de ruptura.

Ahora bien, un factor decisivo en esta última toma de distancia o reflexión sobre el valor de esos textos será el "comentario".

13. «La concepción más amplia de comentario puede incluir (...) casi todos los actos y artefactos humanos (...) Como diría un deconstruccionista contemporáneo, 'todos los hechos, figuras y fórmulas, todas las runas, lecturas y escritos, todas las maneras, ficciones y fantasías, todas las costumbres, convenciones y códigos, y todas las leyes, amores y vidas son interpretación'»" ${ }^{37}$. Pero "en una definición restringida o estricta, un comentario puede referir sólo a una glosa corrida sobre un texto generalmente reconocido como clásico o escriturístico ${ }^{38}$.

En este sentido, el comentario viene a ejercer sobre el texto una doble acción: no sólo es la expresión del reconocimiento de una autoridad y valor en el texto; es también una constitución y reforzamiento de esa autoridad y valor. El texto, en efecto, es comentado porque es valioso; pero también tiende a parecer valioso por haber sido merecedor de un comentario. Esto explica que el comentario haya precedido con frecuencia a la compilación de los clásicos o las escrituras en la mayor parte de las civilizacio-

\footnotetext{
${ }^{35}$ Henderson, 39.

${ }^{36}$ Henderson, 40.

${ }^{37}$ Henderson, 64; y ver Leitch 1983, 250.

${ }^{38}$ Henderson, 62.
} 
nes y haya así tenido parte activa en la constitución del propio canon. Precisamente ahí estaría uno de los factores clave en la determinación del carácter histórico de la constitución de los diversos cánones en las distintas culturas. Pero no sólo interviene de este modo general en la canonicidad de los textos, sino también definiendo las condiciones intrínsecas de la propia canonicidad. Este es, en efecto, uno de los motivos que más a menudo provocan el comentario: la necesidad de probar que un texto o canon determinados cumplen realmente tales condiciones ideales.

Un catálogo comparativo de lo que ocurre en muy distintas culturas, nos permite enumerar hasta siete constantes definitorias de cómo es un canon: (1) un canon es o tiende a ser visto como un algo enciclopédico; (2) un canon está constituido por una pluralidad ordenada o coherente; (3) un canon es un todo internamente autoconsistente; (4) un canon es moral; (5) un canon es profundo; (6) un canon no contiene nada superfluo o trivial; y (7) un canon es claro y accesible a todos. Estas constantes aparecen en mayor o menor grado en relación a todos los cánones conocidos, con independencia de que algunas de ellas resulten de hecho contradictorias respecto a las consecuencias de otras constantes: p.e. la (7) puede coexistir con técnicas muy sofisticadas y elitistas de interpretación, necesarias para salvar la validez de constantes como la (1), (2) y (3) en muchas culturas...

Vamos a decir algo sobre las constantes (1), (2) y (3), incluyendo en esta última la (6), por ser las que, como veremos, más operativas parecen con el peculiar modo de canonicidad que presenta el clasicismo greco-romano.

14. (1) «El supuesto más universal y más ampliamente expresado en relación con el carácter de casi cualquier canon es que es comprehensivo y omniabarcante, que contiene todo significado y toda verdad ${ }^{39}$, si no siempre de manera explícita o diáfana, sí al menos de manera virtual o cifrada. Por eso se ha dicho que

\footnotetext{
${ }^{39}$ Henderson, 89.
} 
«donde hay un canon podemos predecir la necesaria aparición de un hermeneuta ${ }^{40}$, que venga a poner a flote o a sacar a la luz lo que está oculto o es oscuro. Dentro de cada contexto cultural, de este modo son vistos los textos canónicos que les son propios: para los judíos, el PENTATEUCO es «el libro que lo contiene todo" y Neusner llama al TALMUD babilónico «la gran aspiradora (vacuum cleaner) del judaísmo»; la obra aristotélica era, para los medievales, "una enciclopedia del saber antiguo», y otro tanto era HOMERO para Platón, los alejandrinos o el Pseudo-Plutarco; o el MAHABHARATA o el POPOL-VUH para sus respectivos comentadores y creyentes. «Los términos con que los comentaristas de las distintas tradiciones proclaman la comprehensividad de los distintos cánones, en general como una verdad por sí misma evidente no abierta a discusión o debate, son notablemente semejantes (...) desde el Vinoso Ponto de Homero al mapa del Río Amarillo de Confucio, con una detención junto a las aguas de Babilonia donde los Talmudistas recordaron a Sión...." ${ }^{41}$.

(2) «El segundo supuesto comentarístico más común... es que los cánones o textos canónicos están bien ordenados, de forma coherente, según principios o criterios que pueden ser de orden lógico, cosmológico o pedagógico» ${ }^{42}$. Esta necesidad de contar con alguna pauta de estructura $\mathbf{u}$ orden para entender parece una servidumbre muy tenaz de la intelección humana. Por ello será un buen distintivo de una adecuada gestión exegética la capacidad para organizar una pluralidad canónica, aunque sea con razones tan peregrinas como las que han inventado algunos exégetas para salvar la unidad de la Biblia o de la obra homérica. La tradicional obsesión por lograr un criterio de orden interno que articulara toda la producción platónica -Schleiermacher- es un ejemplo de esta constante. Teniendo en cuenta que, cuando toda hipótesis parezca inviable, queda aún el recurso de atribuir a los padres del canon

\footnotetext{
${ }^{40} \mathrm{Ib}$.

${ }^{41}$ Henderson, 91 y ss.

${ }^{42}$ Henderson, 106.
} 
alguna extraña intención pedagógica. Los dioses también se prestan a jugar a los acertijos para poner a prueba nuestro ingenio: con afirmaciones de éstas ponen a prueba el suyo los hermeneutas.

(3) «Un tercer supuesto comentarístico general... es el de que el canon es autoconsistente, que las contradicciones internas que hay en él son sólo aparentes; y éste es un asunto de más vital importancia que los otros dos. Los partidarios modernos de una tradición, los creyentes, pueden admitir que su canon no es comprehensivo, que no incluye todo conocimiento o toda verdad. Pueden encontrar algún lugar en el mundo para el saber secular, filosofía o ciencia. Pueden también reconocer que su texto clásico o escriturístico carece de algo en cuanto a orden o coherencia. Las revelaciones y proferencias divinas, después de todo, a veces proceden a tontas y a locas, y no siempre observan las pautas formales del retórico clásico. Pero admitir la existencia de contradicciones internas significativas en el canon es asunto de mucha mayor monta, puesto que desintegra seriamente los cimientos de la pretensión canónica a la verdad. Porque la verdad, aunque no sea realmente una e indivisible, debe al menos, según la mayoría de las estimaciones, no ser autocontradictoria.... ${ }^{43}$.

Junto con la constante (6), la idea de que no debe haber en el canon nada superfluo o trivial, será ése uno de los caballos de batalla de la hermenéutica filosófica lo mismo que bíblica.

15. Las convenciones que determinan el acceso al estatuto de canonicidad operan básicamente en el orden de lo que hemos llamado ideología blanda o sutil. Dejando de lado el análisis comparativo de las estrategias generales a que eso da lugar en el comentario -en la práctica, las exigencias que desde esas convenciones se le imponen al texto, tienen que ser justificadas contra toda evidencia ${ }^{44}$, vamos a considerar algunos rasgos específicos de ese peculiar canon de la clasicidad greco-romana.

\footnotetext{
${ }^{43}$ Henderson, 115.

${ }^{44}$ Ver Henderson, 168.
} 
Podríamos resumir esos rasgos en la afirmación de que se trata de un canon que es objeto de una doble promulgación -o de una promulgación y uno o dos ajustes posteriores- ${ }^{45}$. La primera de estas promulgaciones se produce en lo que sería su contexto "propio" o su medio normal; la otra o los ajustes posteriores se producen, por el contrario, en relación a otro canon, el cristiano neotestamentario o el área de pensamiento que éste acota.

La primera promulgación tiene efecto en el mundo helenístico. Raymond Quéneau ${ }^{46}$ la describe así: «en tres siglos, en el dominio literario, los clásicos lo inventan todo. En tres siglos más, los alejandrinos hacen otro descubrimiento no menos genial: inventan el clasicismo». La afirmación de Quéneau tiene dos partes que la hacen especialmente significativa: en la primera se muestra fiel observante de las convenciones que definen un $\operatorname{canon}^{47}$. $Y$, en la segunda parte, hace en realidad dos cosas: nos dice quiénes promovieron a esta condición de canonicidad a los "clásicos", y lo dice de tal manera que él mismo a su vez atribuye valor canónico a esa promoción. Con lo que consagra el carácter de verdad-valor intocables a todo lo que acompaña a aquélla: al hecho de la canonización, al comentario que ella va a inducir y a la teoría retórico-literaria que lo va a sustentar.

Las imposiciones en régimen de gratuidad ideológica no se limitan a eso. El estatuto de canonicidad "clásica", en efecto, eleva a categoría un cierto tipo de producto cultural; un producto cultural que se define a) por unas cualificaciones internas $y b$ ) por unas concretas coordenadas de lugar y tiempo. Ahora bien, si la idea de "categoría" lleva aparejada la de una cierta universal validez, el factor b) impide esa promoción de algo histórico a categoría. Sólo es entonces posible acceder a la canonicidad o bien separando el

\footnotetext{
${ }^{45}$ Véase, antes 12.

${ }^{46} 1977$, p. XV.

${ }^{47}$ Ver antes, 14. Nótese lo no evidente de la afirmación: el hecho de la invención de ese "todo" dejaría de ser excepcional si sólo hubiera dos o tres cosas que inventar; o, si hubiera más, podría igualmente sugerir escasa capacidad inventiva en los epígonos. Las escalas de referencia son opcionales...
} 
factor a) del b) -de modo que el factor a) pasa a ser origen absoluto en lugar de ser un feliz hallazgo en una época brillante-; o bien embebiendo a) en el factor b) -con lo que lo clásico acaba por ser toda la época, que es la que garantiza la "calidad" de clásico a todo lo que accidentalmente viene a caer en ella. El clasicismo ha fagocitado a los clásicos. La confusión de valores está servida.

En la práctica, hay una oscilante indefinición entre ambos modos de proceder y una ecléctica manera de hacerlos coexistir más bien poco coherente. Aunque en los cánones lo que importa es hacer pasar como coherencia lo que difícilmente se sostiene como tal: ésta es la tarea del comentario, nunca criticar el canon y menos aún rectificarlo. Abandonar de esta manera la canonicidad sería entrar en la filosofía -al menos tal como parece la entendía Aristóteles-.

Sea cual sea la forma que adopte esta cohabitación, el hecho es que se ha instituido como paradigma algo que era de suyo sencillamente "histórico", una creación humana tan rica como se quiera pero "situada", relativa-a, inmersa-en, etc., etc. Las virtuales consecuencias de este desplazamiento semántico son todo menos inocentes: - la reducción de la validez de todo proceso futuro a la reiteración del modelo; -la resistencia a priori a todo lo nuevo, el rechazo frontal a todo lo que cuestione el modelo o lo altere, etc.; moralización del modelo -cuarto rasgo constitutivo de un canon: ver 13.-: él es la única fuente de valores morales del hombre; inclinación a vivir de la nostalgia de todo tiempo pasado, "siempre mejor"; -insensibilidad ante la idea de estar convirtiendo en valor universal lo que es étnica y cronológicamente particular y hasta incluso, dentro de un espacio étnicamente cerrado, ideológicamente sesgado (p.e., Sócrates-Platón-Aristóteles, en el marco, del s. VIV ateniense); etc., etc.

16. Preguntémonos, por fin: ¿en qué contexto, de qué manera tienden a actualizarse estas virtualidades? 
Hemos hecho referencia antes a una segunda promulgación o equivalente del canon clásico en el mundo occidental. Ha llegado el momento de decir algo al respecto.

$\mathrm{Si}$ el humanismo de los ss. XV-XVI, en cuanto bandera de modernidad y progreso contra los medievales, podía verse como una cierta reactualización de la proclamación canónica de los alejandrinos, tan pronto el estudio de los antiguos pareció haberse instalado por su propio peso en el espacio cultural de Occidente, se hizo inevitable en ello un cierto ajuste, casi equivalente a una nueva promulgación. El primer momento de ésta se produjo con un carácter más bien agresivo y formal de la mano de la Ratio Studiorum de los jesuítas, que incorporó a su sistema educativo para las clases altas el estudio de los clásicos y sus lenguas como factor formativo básico, por más que los textos debieran ofrecerse cuidadosamente expurgados ad usum delphini ${ }^{48}$. El valor de "progresía" de los mismos quedó anulado automáticamente.

A su vez, en la Europa de la Reforma, el centro de la atención intelectual vendrá a ocuparlo la Escritura, y su medio de acceso más propio: la lectura. Ahora bien, el presupuesto de la Reforma era que la Biblia había de ser unitariamente inteligible -requisitos canónicos (1) y (2): ver antes-, y ello suponía la puesta a punto de una técnica filológica específica. La recuperación humanística de la filologia alejandrina y el antecedente agustiniano -DE DOCTRINA CHRISTIANA- del empleo de la retórica para hallar las "reglas" de manejo del texto, fueron dos antecedentes capitales para la primera teorización exegética de la Reforma, la CLAVIS SCRIPTURE SACRAE, de Matthias Flacius Illyricus (1577). Según Flacius, «la Biblia debe ser considerada como un conjunto..., expresión, a través de la diversidad de los espacios y los tiempos, del único designio de Dios. El presupuesto de la coherencia ontológica subtiende al conjunto de la interpretación; las dificultades y ambigüedades encontrarán clarificación en la referencia a la totalidad $"{ }^{49}$. Además, «al haber adopta-

\footnotetext{
${ }^{48}$ Ver Gusdorf 1988, 102.

${ }^{49}$ Ver Gusdorf 1988, 127.
} 
do el lenguaje de los hombres, Dios debe haber puesto en obra los principios generales del discurso humano, codificados por la retórica de Aristóteles" ${ }^{50}$.

Tomada en su conjunto, se hace difícil imaginar qué puede tener que ver la teoría de la persuasión de la verdad, p.e., con la interpretación de la Escritura. Parece, pues, que hemos de entender aquí retórica a la luz de los principios que Flacius ha enunciado antes y que corresponden más bien a lo que se tomaba por retórica en la época helenística, una técnica o preceptiva oratoria básica. En este marco, en efecto, tiene sentido la exigencia de que en un discurso las partes obedezcan a la totalidad del plan establecido, y de que el discurso sea como un todo orgánico en el que todo tenga su función y papel, sin nada superfluo, etc. Normas de composición que se traducen luego en pautas de valoración ante los discursos ya hechos. Ahora bien, ninguna preceptiva puede garantizar que esos ideales se cumplan en los discursos concretos que los humanos vayan a componer: ellas marcan el ideal, el talento lo pone el que lo tiene... ¿En qué supuestos podría tomarse una preceptiva retórica en ese sentido?.

Hay un primer supuesto claro. En la mediación de una profesión de fe, contenida ya en la mera consideración de un conjunto de textos como Escritura sacra, el autor del discurso cumple con las condiciones básicas para realizar la obra perfecta: un ser divino infinito en su inteligencia, en su capacidad de realizar un discurso perfecto y sin fisuras, etc. ¿Cómo imaginar o aceptar, supuesta la profesión de fe, que pueda haber falta de unidad y se digan incoherencias en un discurso divino? A la menor sospecha de tal cosa, la estrategia exegético-comentarística se pone automáticamente en marcha: aclarar, analizar, explicar, salvar la cohesión a toda costa, son sus cometidos. $Y$, si tal cosa no resulta fácil dada la mediación previa de amanuenses humanos, habrá que buscarla más allá de las apariencias, en las intenciones "ocultas" de su autor divino.

\footnotetext{
${ }^{50}$ Ibid.
} 
Hasta aquí todo es consecuente con el marco que se establece desde el supuesto radical de que se parte: tiene que haber cohesión, sentido unitario. Pese a todo, sin embargo, la tenaz labor filológica, crítica, histórica incluso con que se apremia al texto a dar lo que contiene, erosiona irremediablemente algo de esa fe originaria, que busca entonces reformularse para no perderse en la nada. Se incorpora así al contenido la idea de "historia": la revelación está no en un sentido que el texto brinda de una vez por todas, sino en el conjunto de las manifestaciones de sentido que se dan en las diferentes épocas. El saber filológico de la Escritura se hace así saber acumulativo, y la tradición es el cordón umbilical que vincula a su "origen" nutricio cualquier expresión de sentido. Todavía estamos en el área de coherencia que delimita un acto de fe inicial.

17. Sin embargo, a partir de ahí, en una serie de mediaciones apenas perceptibles, casi infinitesimales, estos mecanismos de estrategia hermenéutica son transferidos a la filología de los textos de la antigüedad clásica, por medio de una teoría "general" de la interpretación. Ahora bien, para que tal teoría fuera efectivamente "general" había que actuar a contrapelo de toda especialización técnica y de cualquier progreso analítico, optando por el contrario a favor de ciertas operaciones de ajuste que la hicieran posible. La primera de estas fue reducir a un único concepto de significado o sentido tanto lo que acuñaba como significado el habla y el lenguaje (y que se había encargado de aclarar ya la hermeneia aristotélica) como aquel sentido que, en una operación retrodictiva o análoga, un observador pudiera conferir a un hecho o acción, desde un particular punto de vista. De modo que se encerraba en una metafórica y equívoca "producción de sentido" todo un conjunto de hechos suficientemente heterogéneos como para mantenerse separados. La segunda fue abolir la diferencia entre los contextos de producción y lectura de los textos profanos y sagrados. Tal abolición se produjo en una serie de pasos o fases. El principio de someter a un mismo tratamiento exegético unos y 
otros textos se había ido afianzando ya en la exégesis del s. XVII. Pero aun en ese caso seguía vigente la profesión de fe que confería al texto sacro una intención distinta e irreductible. Esto es precisamente lo que quiso reforzar el pietismo de fines del s. XVIII, poniendo el acento de la lectura sagrada en la experiencia personal del texto, en la comprensión del mismo. Con ello la exégesis se hacía hermenéutica y comenzaba a girar en torno al concepto hondamente equívoco de verstehen. Una primera mediación parece relacionada con el mito del "genio" que, inmerso en "la circulación de la espontaneidad vital" -otro mitema romántico-, dará a la obra una cualificación nueva ${ }^{51}$. Al tiempo que se impondrá a todo texto por el mero hecho de serlo -es decir, no ya por proceder de una supuesta inspiración divina- el Kanon der Ganzheit, que implica de hecho una lectura en "clave trascendental" de lo que en la retórica convencional fueron modestos preceptos para uso de aprendices de orador. No importaba que, en la práctica, muchos de esos textos se mostraran al mero sentido común como torpes centones de heterogéneo material de aluvión. Una vez más, como en todo "canon", la coherencia se ha de aceptar y es cometido del comentario y sus convenciones ponerla a salvo. Cosa tanto más fácil ahora cuanto que ya Hegel había puesto al día la idea del "ardid de la razón" -versión ad hoc del principio "canónico" tradicional ya mencionado; que Gadamer oportunamente recuperará $(1977,377)$ para explicarnos qué se esconde tras su "fusión de horizontes"-. De hecho -sin detenernos ahora en las etapas de esta hermenéutica ${ }^{52}$ - nos encontramos ante una nueva versión del texto de Agustín de Hipona antes citado, sólo que revestido de sofisticados ropajes intelectuales. Sin excluir en todo ello una

\footnotetext{
${ }^{51}$ Ver Gusdorf 259; la presencia de la idea de Erlebnis en alianza con la 'comprensión' está ya en Schleiermacher; y recuérdese cómo éste -exégeta y predicador protestante mucho más que filósofo: Gusdorf 304, Quillien 1990 passimconcibe la figura de Platón a la hora de editar sus obras: Dilthey VII, 333.

${ }^{52}$ Ver sobre ello Gusdorf, 188; y Quillien, 78 y passim.
} 
decidida voluntad "pastoral" de salvar valores y conjurar nihilis$\operatorname{mos}^{53}$.

Si la consecuencia última de la "canonicidad" clásica fue la concesión del distintivo "clásico" a cualquier producto cultural situado en una determinada época, al margen de sus cualificaciones intrínsecas, el movimiento "canónico" que alienta en esta hermenéutica hace de todo texto -o de todo lo que le sea asimilable- un "revelador de sentido" por el mero hecho de ser texto, sea cual sea su calidad intrínseca, y convierte en "acumulativa" producción de saber la paranoia interpretativa que lo acompaña.

IV.

18. Este rodeo por los modos sutiles de promoción "canónica" de algunos supuestos y procedimientos propios de los llamados estudios clásicos y humanísticos, nos habrá de permitir un replanteamiento crítico de la pregunta inicial del ensayo.

En esa cuestión inicial - ¿¿Humanidades en una era tecnológica?"-, encontrábamos de entrada dos cosas: a) una cierta oposición o desleal competencia entre humanidades y tecnología, con un desplazamiento de las primeras por la segunda; $y$ b) una pregunta acerca de la vigencia de los argumentos tradicionales en pro de esta clase de estudios. $Y$ en esta segunda cuestión, nos planteábamos dos posibilidades: ba) la de revitalizar sin más los argumentos tradicionales, o bb) la de buscar argumentos sustitutivos si aquellos habían perdido fuerza. Sin embargo, los presupuestos vigentes en ese momento excluían de nuestro planteamiento una alternativa que se hace imperativo considerar ahora: no basta, en efecto, con preguntarse acerca de los argumentos en pro o en contra: hay que preguntarse también acerca de la adecuación o no de los estudios humanísticos tradicionales de cara al fin propuesto,

\footnotetext{
${ }^{53}$ Ver Gadamer, Prólogo a la $2^{\mathrm{a}}$ ed. y su sintomático recurso a la subtilitas aplicandi que toma de las INSTITUTIONES HERMENEUTICAE SACRAE de J.J. Rambach, 1723.
} 
"una apropiada formación humanística". Las posibilidades a examinar en el apartado b) quedarán, pues, de esta manera: ba) valen los argumentos y valen los estudios tradicionales; $b b$ ) no valen los argumentos usados hasta ahora pero sí esos estudios; $b c$ ) no valen los argumentos -al menos en su formulación habitual- y tampoco esos estudios en la forma hasta ahora adoptada: hay que cuestionarse a fondo ambas cosas, el modelo de estudios humanísticos y los motivos que apoyen su difusión y promoción.

Veamos brevemente lo que esto significa.

a) En la oposición humanidades-tecnología no es prudente decantarse demasiado a priori en la cuestión de decidir en quién recae la responsabilidad del desplazamiento de las primeras por la segunda. Ante todo, es posible que la incomprensión sea mutua: como escribe Canfora ${ }^{54}$, "clasicidad en cuanto paradigma será la forma suprema de limitación del discurso, de rechazo precavido a las palabras de los demás. La idea de un discurso hecho de una vez para siempre, y que proporciona, a cualquier otro discurso posible, no sólo las formas, sino también los contenidos. En el fondo se tratará, evidentemente, de la inclinación a considerar como absolutamente válidas determinadas formas de pensamiento...» De entrada, pues, la condición paradigmática de lo clásicohumanista implica e impone una predominante gravitación hacia el pasado y una desconfiada reticencia hacia lo nuevo.

Esto, con todo, no es la totalidad del problema. Por su parte, el señuelo tecnológico -con reclamos tan operativos como el de la eficacia práctica, la inmediatez del resultado y del goce, la economía de esfuerzo personal o la capacidad de halago sensorial, por citar algunos- parece tener más éxito social que las propuestas humanisticas. Por más que esto pueda tomarse como un hecho, culpar de ello a la tecnología es más bien aberrante. La "tecnología" es una abstracción solo. Entre ella y los humanismos están los individuos concretos, que actúan por motivos. Se trata, pues, de averiguar por qué una opción es mucho más motivadora que otra.

\footnotetext{
${ }^{54}$ Canfora, 242.
} 
Haciendo de la tecnología el chivo expiatorio de un fracaso, no hacemos más que repetir el gesto de la filosofía culpando de su crisis interna a factores exógenos, con tal de no repensar su propia historia y afrontar su ensimismada autocomplacencia en lo que es acaso mera repetición estéril de sí misma y de lo ya pensado, y olvido de una revisión de su pensar y sus supuestos. ¿Por qué son más estimulantes las motivaciones que pone en juego la tecnología? ¿Son los estudios humanísticos capaces de esgrimir razones equivalentes? ¿Cuáles, las tradicionales $u$ otras?

Todo esto nos remite al punto b) de nuestro planteamiento anterior.

19. Alternativa que afrontaremos de forma más directa si centramos nuestra atención en la cuestión bc), que en definitiva incluye la referencia a las dos anteriores. Veámos entonces la posibilidad allí enunciada en sus dos aspectos: 1) el que atañe a los argumentos con que defender la necesidad de tales estudios; 2) el que afecta a la constitución misma de tales estudios.

1) Aunque revestidos de variopintos ropajes, los argumentos que abogan por los estudios clásicos y humanísticos suelen estar siempre viciados en algún grado por los condicionantes que dimanan del estatuto "canónico" de la clasicidad: "los clásicos" encarnan el prototipo y el paradigma de lo que ha de ser tenido como "humano" o como "valor humano" universal. No importa que se arguya que, de hecho, tales valores sólo fueron posibles en una sociedad estratificada con criterios elitistas, que quienes encarnaron en ella tales valores fueron precisamente la minoría dominante, de la que surgió la filosofía -la que domina la tradición- que justificó teóricamente esas diferencias. Y no importa que esos valores puedan estar consagrando un abuso etnocéntrico injustificado, para el que todo lo demás es "barbarie" incalificable. Tampoco importa que, dentro del largo espacio de la cultura greco-romana, el "modelo" en cuestión haya sido puesto en tela de juicio en más de un momento o haya pertenecido sólo a una porción escasa de ese todo. No importa, sobre todo, que tan 
sagrado modelo sólo pueda sobrevivir encerrado en contemplativas torres de marfil, donde no lo alcance la doliente marea humana que nos acosa desde los media -artefactos de tecnología después de todo- y que pone en entredicho a cada paso el valor y la utilidad de tal modelo. Todo eso no importa.

Sí, en cambio, parece importar mucho hacer hincapié en los estrechos lazos de continuidad y filiación que nos atan a ellos, sin analizar críticamente cosas como $i$ ) si esa continuidad aparente es fruto más bien de una reducción al mínimo o una falta de sensibilidad frente a las verdaderas diferencias; o si $i i)$ tal hecho es simplemente indicio sintomático de la esterilidad del hombre para darse valores y conceptos nuevos; o iii) si se trata de que la escala de nuestra observación histórica es distinta de la de la evolución y es aún precisa una cierta espera a ver si damos un salto cuántico que nos acerque algo más a la racionalidad. Decir-pensar todo eso suena, en ese contexto, a pura herejía. Porque, después de todo, como bien señala Canfora ${ }^{55}$, «clasicidad en cuanto paradigma será la forma suprema de limitación del discurso, de rechazo precavido a las palabras de los demás. La idea de un discurso hecho de una vez para siempre, y que proporciona a cualquier otro discurso posible no sólo su forma, sino también sus contenidos. En el fondo se tratará, evidentemente, de la inclinación a considerar como absolutamente válidas determinadas formas de pensamiento..." $\mathrm{Si}$ hay, pues, una efectiva repulsión o rechazo entre humanismo y tecnología, ¿no será que también, por parte de aquél, en su forma clásica y paradigmática sobre todo, hay una implícita descalificación a priori de todo lo que no se acomoda a sus convenciones, de todo lo que no respeta la obediencia al origen?.

Tal vez sea esta idea el meollo de todo el asunto: la idea de origen; el mito de un momento de plenitud total no repetible, único, de una mítica Edad de Oro que hace de todo tiempo posterior una mera réplica o copia, sólo valiosa en cuanto servilmente fiel, que viene a desplazar la idea de un hecho histórico

${ }^{55}$ Canfora, 242. 
lentamente acuñado en la sombra y en el contexto de una serie de variables coincidentes, que emerge en un lugar y tiempo concretos y señala el comienzo de una serie impredecible de hechos, una tarea abierta a la libre y responsable intervención de sus actores. En el fondo, ver en esos valores un paradigma definitivo de lo humano refleja una idea muy pobre y pesimista de las posibilidades humanas. $Y$ eso es en su raíz toda teoría que pone su centro de gravedad en un origen: una perenne visión negativa de su presente y su futuro.

2) En cuanto a la cuestión de en qué consisten los estudios clásicos tradicionales, también Canfora nos aporta alguna luz: «Los estudios clásicos se postulan, estructuralmente, como cultura de élite, puesto que constituyen un saber 'acumulativo' por excelencia, en el que se trata de comenzar cada vez desde el principio y avanzar cada vez lo más posible ${ }^{56}$. Por de pronto son elitistas porque, en cuanto estudios exhaustivos sobre la antigüedad griega y romana, exigen un dominio específico de ambas lenguas y sus especificidades históricas. Lo mismo que por ese supuesto requisito de "acumulación", cuyo sentido difícilmente se justifica de manera crítica, antes parece más bien una convención traída de fuera y extemporánea. En el mejor de los casos, la convención se retrotraería a los rituales que dicta el estatuto de "canonicidad" dado a lo clásico: de hecho fue en la filología escriturística donde, a partir de la profesión de fe en el carácter "revelado" del texto, se conjura dogmáticamente la disolución historicista de la revelación mediante la dosificación acumulativa de ésta en el tiempo. Pero nada explica por qué haya de ocurrir algo análogo en una ciencia crítica que estudia hechos y textos humanos, laicos, histórico-culturales, etc.

Si se añade a este modo de constituirse los estudios clásicos, el cruce con principios como el que celebra la reposición de la filología en "la fe de ser tutora y dispensadora de valores"

\footnotetext{
${ }^{56}$ p. 242.

${ }^{57}$ Que ciertos medios asignaron a Wilamowitz: ver Canfora, 39.
} 
pregunta por la idoneidad de unos estudios humanísticos en una era tecnológica se fragmenta en una cascada de inesperadas cuestiones. Ya no se trata tan sólo de ponderar qué razones pueden fundar la conveniencia de unos estudios humanísticos, sino de algo más complejo, a saber, qué vamos a entender por formación humanística, qué contenido daremos a unos estudios que la propicien, y a qué instancias habrá que confiar la tarea de hacerla posible.

20. Explicar qué se entiende por formación humanística puede parecer, en primera instancia fácil: los humanismos de todos los tiempos han inscrito en su bandera el célebre verso de Terencio: Homo sum, humani nihil a me alienum puto. Sin embargo, más de un problema -y no sólo dialéctico- provoca la interpretación de esa parte del verso que habla de humani nihil. Dependerá de si lo tomamos en toda su nuda significatividad o intentamos reducir el humani a algún modo de especiosa definición acuñada en algún aledaño de la realidad. De otra manera: dependerá de si tomamos lo humano en toda su extensión fáctica -incluida en el mismo bote la estupidez, la miseria, el sin sentido...-, o situamos en homo una definición por género supremo y diferencia específica lo suficientemente idealizada como para mantener fuera de juego los datos incómodos, reduciendo lo humano a una razón que sólo unos pocos manifiestan y en uno solo de los múltiples aspectos que la conforman.

La alternativa es capital para cualquier postura que se quiera tomar. En un caso nos encerraremos de nuevo en los a priori de la clasicidad canónica y paradigmática; en el otro, nos veremos forzados a poner en tela de juicio el conjunto de lo que se entiende por formación humanística y a replantear la cuestión desde sus raíces.

De hecho, una vez más, nos encontramos con que la placa tectónica que soporta toda la semántica "humanista" es deslizante y movediza. "Donde por cultura se entiende el 'inmenso capital de conocimientos'...» que mueve la filología, "la cultura será, por 
excelencia, la histórico-humanística y sabio será quien la posee en su mayor parte $»^{58}$. Para decirlo de otra manera: "humanista" es, en ese contexto, el gran erudito, el experto en los secretos últimos de la gran antigüedad greco-romana. Sin embargo se hace bastante difícil imaginar que la manipulación erudita de "las cosas humanas" (tà anthrópina) confiera automáticamente a nadie -ni en el modo de sacramento que imprime carácter ni en el de un nutricio feed-back osmótico- esa capacidad para saberse y sentirse coafectado por todo lo humano. Tanto menos cuanto que eso que proclama como ideal Terencio, el esclavo libio manumitido, afín al círculo helenizante de los Escipiones y más cercano al espíritu del cosmo-polites estoico que al del polites ensimismado de la polis clásica -la de Platón o Aristóteles-, es muy poco compatible con el elitismo humanístico que encarnan esos pensadores del s. IV. Por el contrario, se hace así posible un humanismo de escaparate, tan erudito como se quiera y un poco más, capaz no sólo de definirse y desarrollarse al margen de lo que implica el verso de Terencio, sino también de cohabitar -la experiencia lo ha probado y de qué manera- con propuestas ideológicas difícilmente etiquetables como "humanismo" -llámense elitismo nacionalista, etnocentrismo narcisista, o nazismo-fascismo.

Ante la constante amenaza de ambigüedad, hemos de preguntarnos cómo hay que entender esa dimensión "humanista" que echamos de menos como contrapeso de la centrífuga tecnología que nos desintegra. La respuesta, en efecto, no podrá ser la misma si lo que se pretende es prorrogar la estirpe de los eruditos asegurando de paso trabajo a los colegas del gremio-, o se trata efectivamente de compensar la supuesta pérdida de una tercera dimensión humana, recuperar el tradicional campo de gravitación centrípeta del espíritu, etc. Ahora bien, si es esto último lo que realmente está en juego, ¿tienen algo que ver con ello los modos tradicionales de enseñar las humanidades?.

${ }^{58}$ Ver Canfora, 242/3. 
21. Sea cual sea la respuesta a que se crea llegar luego de una sosegada meditación de los factores en juego, parece además evidente que se impone una ruptura con el "canon". Si optamos por una experiencia humana en libertad, hay que hacer posible que clásico sea, para cada uno, "aquél que no puede serte indiferente y que te sirve para definirte a ti mismo en relación y quizá en contraste con él $\aleph^{59}$. Sólo desde el logro de una experiencia personal como la sugerida, cuya receta no posee como propia ninguna de las tradicionales disciplinas "humanisticas" -filología, filosofía o historia-, es posible acceder a un humanismo libre, creativo, no manipulado, eficaz.

El único que, por añadidura, respondería de forma adecuada a la necesidad humana de memoria. Que el hombre es un ser de memoria lo confirma por doquier la ciencia moderna. El hecho, con todo, requiere una complementaria precisión acerca de qué hay que entender por memoria. Que algunos de los rasgos que nos constituyen en humanidad no se reciben explícitamente codificados en el $A D N$, sino que se adquieren luego del nacimiento por epigénesis es una teoría que se abre paso insistentemente ${ }^{60}$. Somos fruto de una memoria extrauterina, que nos nutre amnióticamente en los primeros años de vida -lenguaje, repertorios de respuestas y fórmulas de vida, de relación social, cuadros de valores... Sin embargo, el acceso a la personal y libre responsabilidad supone una puesta a prueba y una crítica de lo recibido. Más que un cordón umbilical que nos mantenga atados al espacio amniótico de los orígenes, esa memoria ha de sernos el zócalo en que hagamos pie para, arquimédicamente, movernos vitalmente hacia adelante. Sabiendo que no podemos avanzar sin punto de apoyo, que nuestro pensar no piensa desde la nada, sino desde lo pensado previo. Pero sabiendo también que una memoria sana es crítica y selectiva. Y que todo proceso de asimilación implica procesos anabólicos y katabólicos.

\footnotetext{
${ }^{59}$ Calvino, 17.

${ }^{60}$ Changeux 1985, pp. 241 ss., 289 ss.; Thom 1991, 24 ss., 118 ss.
} 
¿Sería esa necesidad de memoria, de una memoria no abrumadoramente impuesta sino libremente manejable por el sujeto, un argumento aún válido a favor de una formación humanista en una era tecnológica?.

BIBLIOGRAFIA citada:

ADRADOS, 1992. RODRIGUEZ ADRADOS, Francisco, PALABRAS E IDEAS, Ediciones clásicas, Madrid, 1992.

AGUSTIN DE HIPONA, DE DOCTRINA CHRISTIANA, en Obras, t. XVI, BAC, Madrid.

BURKERT, 1992. -BURKERT, W. THE ORIENTALIZING REVOLUTION (translated by Margaret E. Pinder \& Walter Burkert), Harvard Univ. Press, Cambridge (Mass.) London (Eng.) - 1992.

CALVINO 1993. -CALVINO, Italo, POR QUE LEER LOS CLASICOS, Tusquets, Barcelona, 1992.

CANFORA 1991. -CANFORA, Luciano, IDEOLOGIAS DE LOS ESTUDIOS CLASICOS, Akal, Madrid, 1991.

CHANGEUX 1985. -CHANGEUX, J. P., EL HOMBRE NEURONAL, Espasa-Calpe, Madrid, 1985.

DILTHEY VII. -DILTHEY, W., ORIGENES DE LA HERMENEUTICA, en Obras de W. Dilthey, VII (pp. 321-336), Fondo de Cultura Económica, México, 1944 (reimpr. 1978).

GADAMER 1977. -GADAMER, H. G., VERDAD Y METODO, Edics. Sígueme, Salamanca, 1977.

GUSDORF 1988. -GUSDORF, Georges, LES ORIGINES DE L'HERMENEUTIQUE, Payot, París, 1988.

HENDERSON 1991. -HENDERSON, John B., SCRIPTURA, CANON AND COMMENTARY, Princeton Univ. Press, Princeton N.J., 1991. 
LAKS/NESCHKE 1990. -LAKS, A./NESCHKE, A., LA NAISSANCE DU PARADIGME HERMENEUTIQUE, Presses Univ. de Lille, 1990.

LEITCH 1983. -LEITCH, Vicent B., DECONSTRUCTIVE CRITICISM..., Columbia Univ. Press, New York, 1983.

LESKY, 1966. -LESKY, A., LA TRAGEDIA GRIEGA, Ed. Labor, Barcelona, 1966. QUÉNEAU 1977. -QUÉNEAU, Raymond, INTRODUCTION vol. I, «Histoire des Littératures", Biblioth. La Pléiade, Gallimard, Paris, Nouv, édit. 1977.

QUILLIEN 1990. -QUILLIEN, Jean, POUR UNE AUTRE SCANSION DE L'HISTOIRE DE L'HERMENEUTIQUE, en Laks/Neschke, 1990 (pp. 69-117).

SANDERS 1987. -SANDERS, James A., CANON AS PARADIGM: FROM SACRED STORY TO SACRED TEXT, Fortress Press, Philadelphia, 1987.

SCHWARTZ 1917. -SCHWARTZ, E. GYMNASIUM UND WELTKULTUR (en Gesammelte Schriften, I, 195- 220).

STEINER 1991. -STEINER, G. PRESENCIAS REALES, Ensayo/Destino, Barcelona, 1991.

THOM 1991. -THOM, René, ESQUISSE D'UNE SÉMIOPHYSIQUE, Interéditions, París, 1988 (2ème tirage corrigé, 1991).

VIDAL-NAQUET 1976. -VIDAL-NAQUET, Pierre, INTRODUCTION a la versión francesa de Moses I. Finley, DEMOCRACY, ANCIENT AND MODERN, París, 1976. 